\title{
Engineered Pichia pastoris production of fusaruside, a selective immunomodulator
}

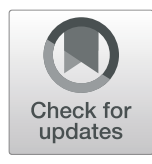

Yuan Tian ${ }^{*}$, Yanling Li ${ }^{1}$, Fengchun Zhao ${ }^{2}$ and Chao Meng ${ }^{1}$

\begin{abstract}
Backgroud: Fusaruside is an immunomodulatory fungal sphingolipid which has medical potentials for treating colitis and liver injury, but its poor natural abundance limits its further study.

Results: In this study, we described a synthetic biology approach for fusaruside production by engineered Pichia pastoris that was based on polycistronic expression. Two fusaruside biosynthesis genes ( $\Delta 3(E)$-sd and $\Delta 10(E)$-sd), were introduced into $P$. pastoris to obtain fusaruside producing strain FUS2. To further enhance the yield of fusaruside, three relevant biosynthetic genes ( $\Delta 3(E)$-sd, $\Delta 10(E)$-sd and gcs) were subsequently introduced into P. pastoris to obtain FUS3. All of the biosynthetic genes were successfully co-expressed in FUS2 and FUS3. Compared to that produced by FUS2, fusaruside achieved from FUS3 were slightly increased. In addition, the culture conditions including $\mathrm{pH}$, temperature and methanol concentration were optimized to improve the fusaruside production level.
\end{abstract}

Conclusions: Here a novel P. pastoris fusaruside production system was developed by introducing the biosynthetic genes linked by 2A peptide gene sequences into a polycistronic expression construct, laying a foundation for further development and application of fusaruside.

Keywords: Fusaruside, P. pastoris, Co-expression, Optimization

\section{Background}

Fusaruside is a kind of sphingolipid, isolated as a minor compound from Fusarium endophytes [1, 2]. It has selective immunosuppression function, and is effective in treating T-cell-mediated colitis and liver injury via adjusting STAT1 signal pathway [3-5]. However, a more detailed study of the effects of fusaruside intake on animal and human health requires significant quantities of pure compounds for dietary research. The natural products for such feeding studies have traditionally been derived from fungal extracts or full chemical synthesis. In the case of fusaruside, such preparation methods may have problems. On the one hand, there are many closely related compounds in the extract mixture of Fusarium sp., on the other hand fusaruside are trace quantity in natrual fungi. Only $24 \mathrm{mg}$ fusaruside could be obtained from about $200 \mathrm{~g}$ crude ethyl acetate extract [6]. Additionally, chemcal synthesis of fusaruside is tedious,

\footnotetext{
*Correspondence: tianyuan2005hit@163.com

${ }^{1}$ College of Life Science, Shandong First Medical University \& Shandong

Academy of Medical Sciences, Taian 271016, Shandong, China

Full list of author information is available at the end of the article
}

inefficient and may cause environmental pollution [7]. As an alternative, we are interested in reconstructing the sphingolipid pathway from Fusarium into metabolic engineered Pichia pastoris, to produce a large number of clinically useful fusaruside.

Based on early study, $P$. pastoris harbours cerebroside $D$ [8] that differs from the precursor of fusaruside, cerebroside $\mathrm{B}$. The only difference to cerebroside $\mathrm{B}$ from $F$. graminearum is the missing of $\mathrm{C} 3$-double bond on the $\mathrm{N}$-Acyl chain. Cerebroside $\mathrm{D}$ can be metabolized by 2hydroxy fatty $\mathrm{N}$-acyl-delta3(E)-desaturase $(\Delta 3(\mathrm{E})-\mathrm{SD})$ to form cerebroside $B$ [9], and further converted into fusaruside in the presence of delta 10(E)-sphingolipid desaturase $(\Delta 10(E)-S D)[10]$. As cerebroside D exists in $P$. pastoris, it is highly plausible to target fusaruside biosynthesis through metabolic engineering of the yeast by co-overexpressing $\Delta 10(\mathrm{E})$-SD and $\Delta 3(\mathrm{E})$-SD (Fig. 1). Moreover, there are two separate pathways of sphingolipid biosynthesis in P. pastoris [8], and cerebroside D can be only produced by one of them. It has been proved that overexpressing glucosylceramide synthase

(c) The Author(s). 2019 Open Access This article is distributed under the terms of the Creative Commons Attribution 4.0 International License (http://creativecommons.org/licenses/by/4.0/), which permits unrestricted use, distribution, and 
<smiles>CCCCCCCCCCCCCCCCCC(O)C(=O)N[C@H](COC(O)C1C(O)C(O)C(CO)C1(C)O)[C@@H](O)C=CCCC=C(C)CCCCCCCCC</smiles>

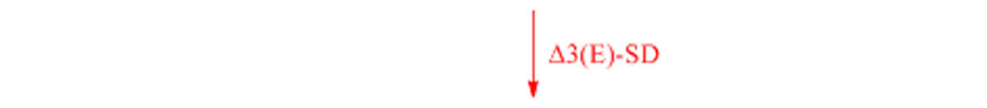<smiles>CCCCCCCCCCCCCCCC=CC(O)C(=O)N[C@@H](COC1(CO)OC(CO)C(O)C(O)C1CO)[C@@H](O)C=CCCC=C(C)CCCCCCCCC</smiles>
$\downarrow \Delta 10(\mathrm{E})-\mathrm{SD}$

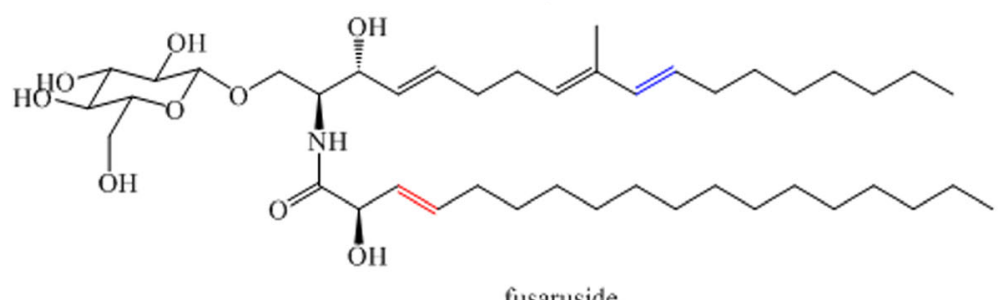

fusaruside

Fig. 1 Engineered fusaruside biosynthetic pathway in P. pastoris. The engineered pathway includes the fusaruside biosynthetic proteins $\Delta 3$ (E)-SD and $\Delta 10(\mathrm{E})$-SD from F. graminearum

(GCS) using the strong $A O X 1$ promoter could enhance the production of cerebroside $\mathrm{D}$.

In this study, we firstly co-expressed $\Delta 10(\mathrm{E})$-SD and $\Delta 3(\mathrm{E})$-SD in yeast expression host systems to obtain fusaruside producing strain, then we co-expressed GCS with $\Delta 10(E)-S D$ and $\Delta 3(E)-S D$ to enhance the yield of fusaruside. The strategy adopted was to engineer yeast using a self-cleaving $2 \mathrm{~A}$ peptide based vector system to realize synchronous production of the enzymes.

\section{Methods}

\section{Chemicals and media}

Restriction enzymes Sac I, SnaB I and Not I were purchased from Takara Bio Inc., Japan, and used as detailed by the manufacturer. Yeast nitrogen base w/o amino acids (YNB), D-sorbitol, Kanamycin monosulfate, Zeocin and geneticin sulfate (G-418S) were obtained from Solarbio, Beijing, China. Oxoid ${ }^{\mathrm{m}}$ peptone and yeast extract were purchased from Thermo Scientific, Germany.

$P$. pastoris was grown in yeast peptone dextrose medium (YPD, $1 \%$ yeast extract, $2 \%$ peptone and $2 \%$ dextrose) or buffered complex glycerol medium (BMGY, $1 \%$ yeast extract, $2 \%$ peptone, $100 \mathrm{mM}$ potassium phosphate,
$\mathrm{pH}$ 6.0, $1.34 \%$ yeast nitrogen base, $0.4 \mathrm{mg} / \mathrm{mL}$ biotin, $1 \%$ glycerol). P. pastoris was induced in buffered complex methanol medium (BMMY, 1\% yeast extract, $2 \%$ peptone, $100 \mathrm{mM}$ potassium phosphate, $\mathrm{pH} 6.0,1.34 \%$ yeast nitrogen base, $0.4 \mathrm{mg} / \mathrm{mL}$ biotin, $0.5 \%$ methanol). YPD plates containing $1 \mathrm{M}$ Sorbitol and $2.5 \mathrm{mg} / \mathrm{mL}$ geneticin sulfate were used for selection of positive strains containing the pPIC3.5 K expression vector. $E$. coli was cultivated in LB medium $(0.5 \%$ yeast extract, $1 \%$ peptone, $1 \% \mathrm{NaCl}) . F$. graminearum was also grown in YPD medium.

\section{RNA isolation}

For RNA isolation, F. graminearum PH-1 (NRRL 31084) was cultured on YPD medium for $72 \mathrm{~h}$ at $28^{\circ} \mathrm{C}$ with shaking of $150 \mathrm{rpm}$. About 3 to $5 \mathrm{~g}$ wet fungal mycelium was collected by filtration on sterile filter paper and used for RNA extraction with the RNAeasy Mini Kit (Qiagen) following the manufacturer's recommendations.

P. pastoris GS115 was grown on YPD medium for $24 \mathrm{~h}$ at $30^{\circ} \mathrm{C}$ and $220 \mathrm{rpm}$. The yeast cells were collected by centrifugation with $5000 \mathrm{rpm}$ and 5 to $10 \mathrm{~g}$ (wet weight) was used for RNA extraction using the RNAeasy Mini Kit. 


\section{Gene amplification and synthesis}

The cDNA was obtained by RT-PCR from total RNA, using PrimeScript ${ }^{\mathrm{tm}}$ 1st Strand cDNA Synthesis Kit (TaKaRa). The DNA fragment encoding the F. graminearum $\Delta 3(E)$-sd gene (GenBank accession: XM_383758.1) was amplified from cDNA by PCR using primers delta3-F (5'-TACGTAGCCACCATGGCCGAACACCTCGTCTTC) and delta3-R (5'-CTGCCTCTTAAACTTCTTC) which contain restriction sites (italicized) for SnaB I.

The F. graminearum $\Delta 10(E)$-sd gene (GenBank accession: XP_390021.1) was amplified by PCR using primers delta10F (5'-ATGGCGCATAGCTCTTTCGTT) and delta10-R1 (5'-GCGGCCGCCTAGTGATGAGAGAGATCACC, $N o t$ I site is italicized) to co-express $\Delta 3(\mathrm{E})$-SD and $\Delta 10(\mathrm{E})$-SD, or amplified using primers delta10-F and delta10-R2 (5'GTGATGAGAGAGATCACC) to co-express three enzymes, $\Delta 3(\mathrm{E})$-SD, $\Delta 10(\mathrm{E})$-SD and GCS. The $P$. pastoris gcs gene (GenBank accession: AF091397) was amplified using primers gcs-F (5'-ATGTCACAACTCAGACCCAG) and gcs-R (5'-GCGGCCGCTTACACTTCAAACCATGA, Not $\mathrm{I}$ site is italicized). The $2 \mathrm{~A}$ polypeptide from the aphthovirus foot-and-month disease virus (FMDV) was selected and synthesized as part of a $66 \mathrm{bp}$ synthetic sequence (5'GGATCCGGAGCCACGAACTTCTCTCTGTTAAAGCAAGCAGGAGACGTGGAAGAAAACCCCGGTCCT) and cloned into pUC19 by BioSune Inc. (Shanghai).

PCR was performed with PrimeSTAR Max DNA Polymerase (TaKaRa) under the following cycling parameters: $30 \mathrm{~s}$ at $98^{\circ} \mathrm{C}$ for a first denaturation step, 30 cycles of $10 \mathrm{~s}$ at $98^{\circ} \mathrm{C}, 15 \mathrm{~s}$ at $55^{\circ} \mathrm{C}$ and $30 \mathrm{~s}$ at $72^{\circ} \mathrm{C}$, and 1 cycle of a final extension step at $72^{\circ} \mathrm{C}$ for $5 \mathrm{~min}$. Reaction mixtures contained $1 \times$ PrimeSTAR Max Premix buffer (including $\mathrm{Mg}^{2+}$, dNTP and polymerase), $0.25 \mu \mathrm{M}$ each primers and $10 \mathrm{ng}$ template in a final volume of $50 \mu \mathrm{L}$.

\section{Construction of co-expression plasmid}

The strategy used to construct the plasmids for coexpression of the proteins described in this study is illustrated in Fig. 2.

To construct two enzymes co-expression vector, the genes $\Delta 3(E)-s d, \Delta 10(E)$-sd and $2 a$ were firstly amplified with delta3-F/delta3-R, delta10-F/delta10-R1 and 2a-F1 (5' - GAAGAAGTTTAAGAGGCAGGGATCCGGAGCCACGAAC)/2a-R1(CGAAAGAGCTATGCGCCATAGGACCGGGGTTTTCTTC) primers, respectively. The products were then fused by splicing overlap extension PCR (SOE-PCR) using delta3-F/delta10-R1 as primer. Finally, the fused gene $\Delta 3(E)-s d-2 a-\Delta 10(E)-s d$ were sub-cloned into pPIC3.5 K, using $S n a B$ I and Not I sites (Fig. 2a).

To construct three proteins co-expression plasmid, the fused gene $\Delta 3(E)-s d-2 a-\Delta 10(E)-s d, g c s$ and $2 a$ were amplified with delta3-F/delta10-R2, gcs-F/gcs-R and 2a-
F2 (5' -GGTGATCTCTCTCATCACGGATCCGGAGCCACGAAC)/2a-R2(5' -GGGTCTGAGTTGTGACATAGGACCGGGGTTTTCTTC) primers, respectively. Subsequently, the products were fused by SOE-PCR using delta3-F/gcs-R as primer. The fused products $\Delta 3(E)-s d-2 a-\Delta 10(E)-s d-2 a-g c s$ were finally sub-cloned into pPIC3.5 K, using SnaB I and Not I sites (Fig. 2b).

The recombinant plasmids were transformed into $E$. coli $\mathrm{DH} 5 \alpha$, and positive transformants were identified by restriction digest analysis and sequencing.

\section{Transformation of $P$. pastoris}

To obtain stable expression strains, the genes in expression vectors (including 5'AOX1, gene of insert, HIS4, Kan and 3'AOX1) were usually transformed to $P$. pastoris and integrated into the genome [11]. The procedure of transformation was performed according to the protocol of Lin-Cereghino [12]. Firstly, the expression vector was linearized with $S a c$ I for integration into the genome of $P$. pastoris. Subsequently, $2 \mu \mathrm{g}$ of linearized plasmids and competent P. pastoris cells were mixed thoroughly and transferred to icecold electroporation cuvettes $(0.2 \mathrm{~cm}$; Bio-Rad, America). The electroporational parameters were set as $200 \Omega, 25 \mu \mathrm{F}$ and $1.5 \mathrm{kV}$. After pulse, $500 \mu \mathrm{L}$ of icecold $1 \mathrm{M}$ sorbitol was added immediately and incubated at $28^{\circ} \mathrm{C}$ for $1 \mathrm{~h}$. After that, another $500 \mu \mathrm{L}$ of YPD was added for further $2 \mathrm{~h}$ of regeneration at the same temperature. After 5 7 days, positive transformants were selected on YPD plates containing 2.5 $\mathrm{mg} / \mathrm{mL}$ Geneticin 418, and then lysed using a combination of enzyme, freezing and heating according to a simple protocol described in the literature [13]. The cell lysates that contain the genomic DNA were analyzed by PCR using the primers delta3-F/delta10-R1 or delta3-F/gcs-R. Linearized vector pPIC3.5 K was also transformed into $P$. pastoris to be used as negative control.

\section{Expression of $2 \mathrm{~A}$ polyprotein constructs in $P$. pastoris yeast} Positive clones were cultured in $10 \mathrm{~mL}$ BMGY medium in a $100 \mathrm{~mL}$ flask at $30^{\circ} \mathrm{C}$ with shaking of $200 \mathrm{rpm}$ until OD600 reaching 12 16. At room temperature, the cultures were collected by centrifugation at $5000 \mathrm{rpm}$ for 5 min. The cell pellets were suspended in $20 \mathrm{~mL}$ BMMY medium and grew under the same conditions $\left(30^{\circ} \mathrm{C}\right.$, $200 \mathrm{rpm})$. Methanol was added to the culture every $24 \mathrm{~h}$ to a final concentration of $0.5 \%(\mathrm{v} / \mathrm{v})$ to induce proteins co-expression. At the same time, $1 \mathrm{~mL}$ of culture medium was collected every $24 \mathrm{~h}$ after initiating induction. The yeast cells were immediately frozen and stored for further sodium dodecyl sulfate-polyacrylamide gelelectrophoresis (SDS-PAGE) analysis. The theoretical molecular weights (MW) of the biosynthetic enzymes 


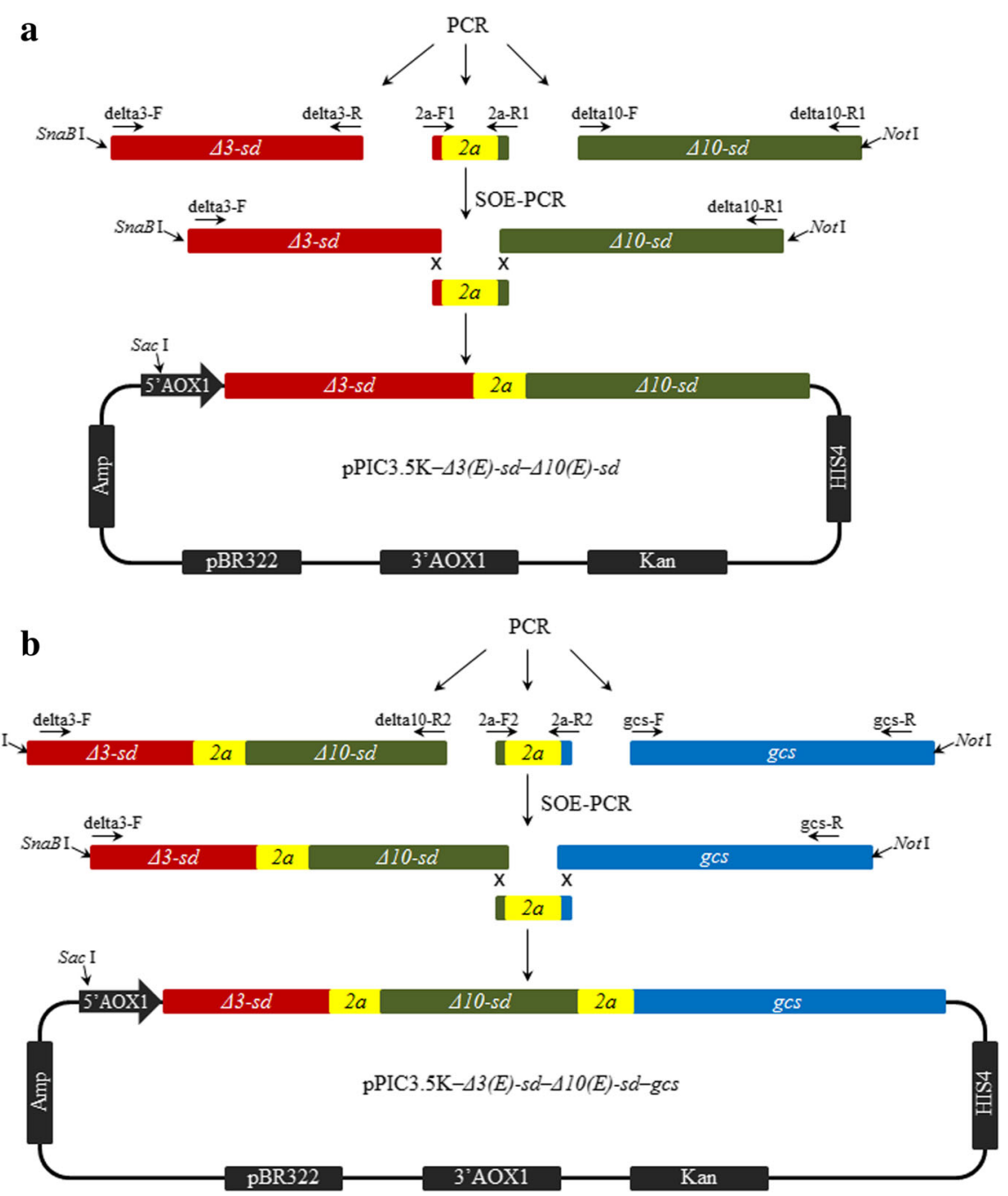

Fig. 2 Schematic diagram showing the strategy for construction of the expression vector pPIC3.5 K- $\Delta 3(E)-s d-\Delta 10(E)-s d(\mathbf{a})$ and pPIC3.5 K- $33(E)$ sd- $\Delta 10(E)-s d-g c s(\mathbf{b})$. Vector construction is described in "Materials and methods"

were calculated using the website http://web.expasy.org/ compute_pi/.

\section{Isolation of sphingolipids}

After $84 \mathrm{~h}$ of induction, P. pastoris cells were treated as described [9]. Approximately $50 \mathrm{mg}$ of dried P. pastoris cells were firstly suspended in $5 \mathrm{~mL}$ of $\mathrm{H}_{2} \mathrm{O}$ and boiled in a water bath for $15 \mathrm{~min}$. Then, the cells were sedimented by centrifugation at $5000 \mathrm{rpm}$ for $5 \mathrm{~min}$ and used to extract sphingolipids. After that, $10 \mathrm{~mL}$ of dichloromethane/methanol $(\mathrm{v} / \mathrm{v}=1: 1)$ was added and shaken overnight at $4{ }^{\circ} \mathrm{C}$ to extract the yeast sphingolipids. The next day, another $10 \mathrm{~mL}$ of dichloromethane/ methanol $(\mathrm{v} / \mathrm{v}=2: 1)$ was added and shaken for at least 4 $\mathrm{h}$ at $4{ }^{\circ} \mathrm{C}$. Subsequently, the $20 \mathrm{~mL}$ of sphingolipid extract was washed three times with dichloromethane/ methanol/0.45\% $\mathrm{NaCl}(\mathrm{v} / \mathrm{v}=8: 4: 3)$. The organic phase (dichloromethane, in the lower layer) was collected and the solvents were removed by a rotary evaporator.

\section{LC-MS analysis and isolation of sphingolipids}

Sphingolipids extracts in organic solvents were analyzed and quantified by liquid chromatography technique coupled with mass spectrometry (LC-MS) as our previous study [10]. To identifiy the compounds in the extract mixture, reference standards (fusaruside and cerebroside B) were used and the derived mass fragmentation spectra were compared. To confirm the structure of fusaruside, sphingolipids extracts were isolated by chromatography and determined by nuclear magnetic resonance (NMR) analysis as described [10].

\section{Optimization of fusaruside production}

In order to increase the production of fusaruside in yeast, culture and induction conditions of engineered 
$P$. pastoris including methanol concentration, $\mathrm{pH}$ and temperature were optimized. All experiments were performed in triplicates.

\section{Results}

\section{Construction of 2A polyprotein cassettes}

Two polyprotein cassettes consisting of $\Delta 3(E)$-sd and $\Delta 10(E)$-sd genes, or consisting of $\Delta 3(E)$-sd, $\Delta 10(E)$-sd and $g c s$ genes, separated by the $2 \mathrm{~A}$ sequences were cloned into the $P$. pastoris expression vector pPIC3.5 K, which is under the regulation of the $A O X 1$ promoter (Fig. 2). The plasmids were further transformed into $E$. coli $\mathrm{DH} 5 \alpha$ to amplify and confirm (see Additional file 1: Figure S1). Double enzyme digestion and sequencing indicated that the genes were correctly oriented in the pPIC3.5 $\mathrm{K}$ vector. The theoretical MW of $\triangle 3(\mathrm{E})-\mathrm{SD}$, $\Delta 10(\mathrm{E})$-SD and GCS were $50 \mathrm{kDa}, 65 \mathrm{kDa}$ and $133 \mathrm{kDa}$, respectively.

\section{Transformation and screening of transformants}

The plasmids pPIC3.5 $\mathrm{K}-\Delta 3(E)$-sd $-\Delta 10(E)$-sd and pPIC3.5 K $-\Delta 3(E)$-sd $-\Delta 10(E)$-sd - gcs were linearized with Sac I and transformed into P. pastoris GS115 competent cells by electroporation, respectively. Positive transformants were selected by the ability to grow on YPD plates containing $2.5 \mathrm{mg} / \mathrm{mL}$ of Geneticin 418 , due to the presence of Kan gene in the pPIC3.5 K vector. The genomic DNA of $P$. pastoris recombinants was isolated to perform PCR verification using delta3-F/ delta10-R1 or delta3-F/gcs-R as primers. One band corresponding to the size of the $\Delta 3(E)$-sd gene plus the $\Delta 10(E)$-sd gene $(\sim 3000 \mathrm{bp})$ were obtained in the chromosome of $P$. pastoris intergrated by pPIC3.5 K $-\Delta 3(E)$-sd $\Delta 10(E)$-sd (see Additional file 1: Figure S2a). In the other P. pastoris recombinant containing pPIC3.5 $\mathrm{K}-\Delta 3(E)$-sd $\Delta 10(E)$-sd $-g c s$, a band corresponding to the size of three genes ( $6000 \mathrm{bp})$ were also detected (see Additional file 1: Figure S2b).

\section{Expression of polycistronic constructs encoding fusaruside pathway}

Two clones named FUS2 and FUS3 were selected to detect enzymes co-expression under inductive conditions. Yeast cells collected after a 4-day induction with methanol were analyzed by SDS-PAGE. The cells from clone FUS2 showed two major induction bands at approximately 50 $\mathrm{kDa}$ and $65 \mathrm{kDa}$ (Fig. 3, lane 2), and three target bands at approximately $50 \mathrm{kDa}, 65 \mathrm{kDa}$ and $133 \mathrm{kDa}$ were observed in FUS3 cells (Fig. 3, lane 3). A yeast strain transformed with pPIC3.5 K was used as control (Fig. 3, lane 1), and no target band was detected in the cells of an induced transformant harboring an empty plasmid. The results thus confirming that the fusaruside biosynthetic enzymes had been successfully co-expressed.

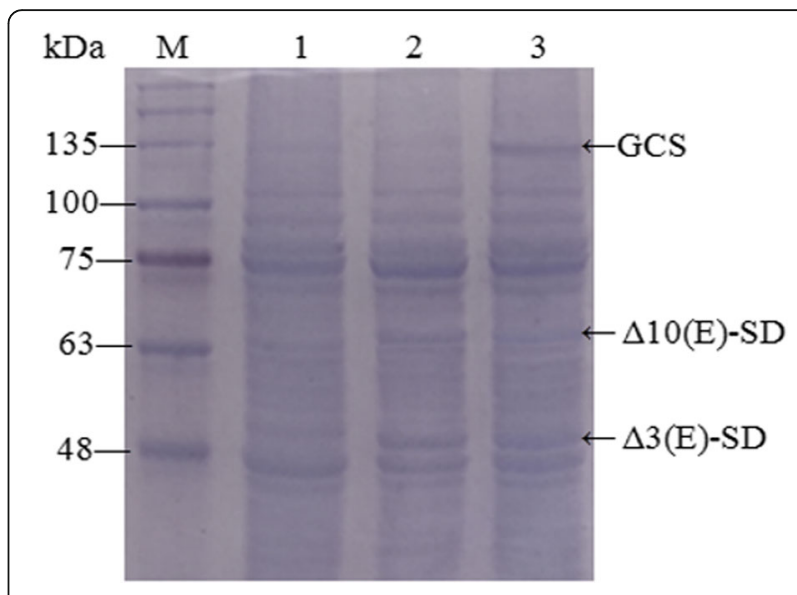

Fig. 3 SDS-PAGE analysis of proteins in recombinantyeasts induced with $0.5 \%$ methanol for $96 \mathrm{~h}$. M: protein molecular weight marker (Solarbio); lane 1: pPIC3.5 K (negative control); lane 2: clone FUS2; lane 3: clone FUS3. The position of the bands corresponding to $\Delta 3(E)-S D, \Delta 10(E)-S D$ and GCS is indicated by arrows

\section{Analysis of sphingolipids in $P$. pastoris strains}

Sphingolipids extracted from the $P$. pastoris transformants were analyed by LC-MS. As displayed in Fig. 4, the co-expression of the desaturases $\Delta 3(\mathrm{E})-\mathrm{SD}$ and $\Delta 10(\mathrm{E})-\mathrm{SD}$ from $F$. graminearum led to the formation of unsaturated fatty acids, cerebroside $\mathrm{B}$ and fusaruside. Compared with that in the strain FUS2 carrying two genes, the yield of fusaruside in FUS3 harboring three genes was slightly increased. While sphingolipids extracted from negative control, $P$. pastoris transformed with pPIC3.5 K, produced no cerebroside B or fusaruside. The sphingolipids production was quantifed by LCMS. Strain FUS2, which co-expressed two enzymes, produced $1.01 \pm 0.17 \mathrm{mg} / \mathrm{g}$ ( $\mathrm{mg}$ of product per gram of sphingolipids crude extracts) cerebroside $B$ and $0.39 \pm$ $0.04 \mathrm{mg} / \mathrm{g}$ fusaruside. The cerebroside $\mathrm{B}$ and fusaruside produced by strain FUS3 were $1.25 \pm 0.22$ and $0.52 \pm$ $0.06 \mathrm{mg} / \mathrm{g}$, respectively. The identity of cerebroside B and fusaruside isolated from $P$. pastoris transformants were also confirmed by NMR spectroscopy. The ${ }^{1} \mathrm{H}$ NMR spectra of cerebroside B (see Additional file 1: Figure S3) and fusaruside (see Additional file 1: Figure S4) were identical to those of authentic materials $[9,10]$.

\section{Optimization of growth and induction}

Three different culture conditions including $\mathrm{pH}$, temperature and methanol concentration were optimized to improve fusaruside production in shake flask, due to their importance for $P$. pastoris expression system $[14,15]$. After $120 \mathrm{~h}$ of induction under different conditions, all the biomass concentrations (OD600) could reach to maximum $(\sim 8)$.

The strain of FUS3, co-expressing three enzymes, was investigated in BMMY media at different $\mathrm{pH}$ levels (4.0, 


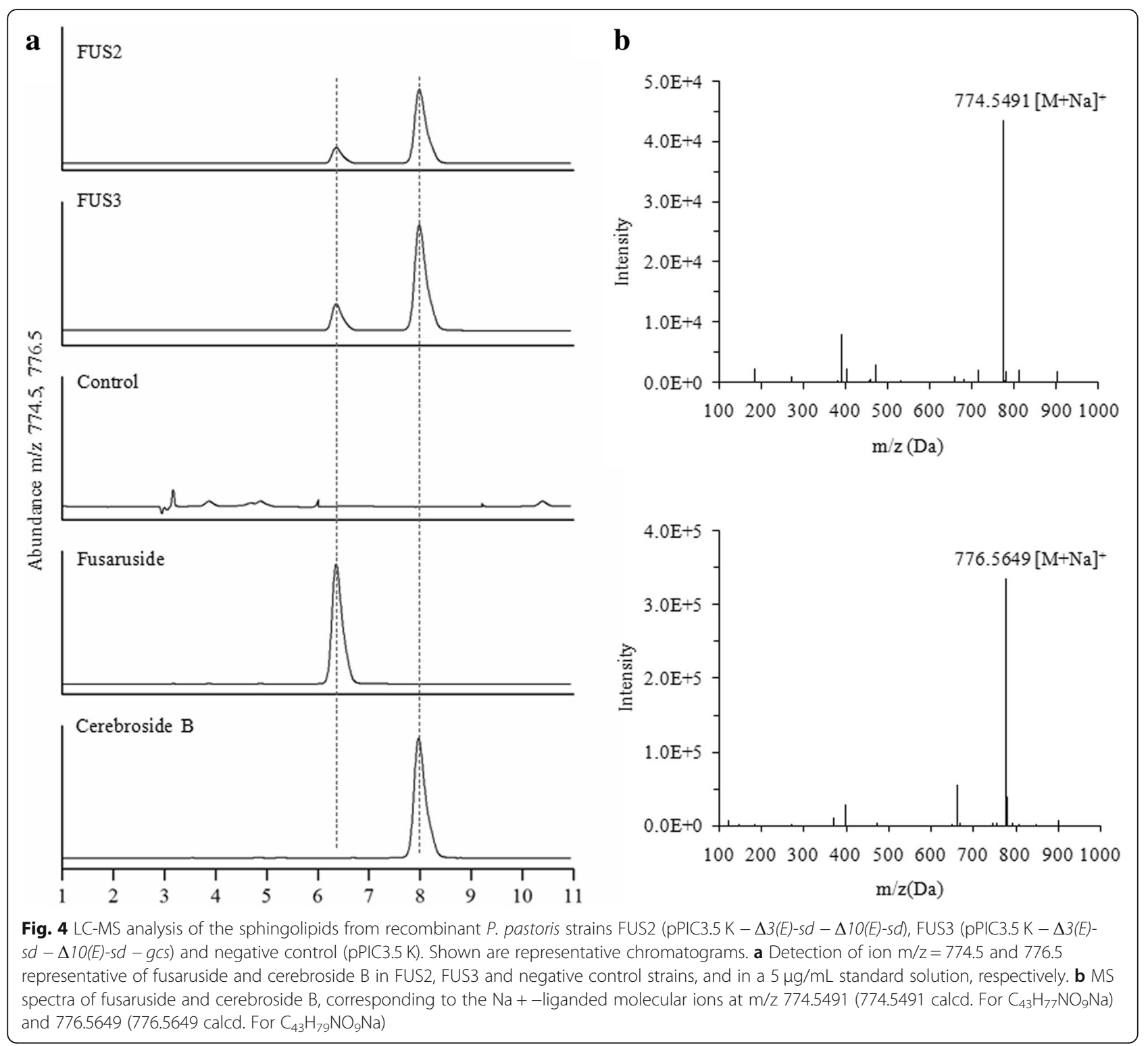

5.0, 6.0, 7.0 and 8.0). As shown in Fig. 5a, the maximum yield of fusaruside was observed at $\mathrm{pH}$ 6.0. In order to optimize methanol concentration, various final concentrations of methanol $(0.5,1,2$ and $3 \%)$ was applied to induce enzyme co-expression in BMMY. The results in Fig. 5b demonstrated that the best methanol concentration for fusaruside production was $1 \%$. Finally, FUS3 was cultivated at 15, 20, 25 and $30{ }^{\circ} \mathrm{C}$ in order to find the optimum temperature for fusaruside production. The results in Fig. $5 \mathrm{c}$ indicated that highest yield was reached at $20^{\circ} \mathrm{C}$. After optimization, high level $(0.74 \pm 0.08 \mathrm{mg} / \mathrm{g})$ of fusaruside was obtained in engineered $P$. pastoris FUS3 strain after $120 \mathrm{~h}$ induction at optimum condition ( $\mathrm{pH} 6.0,1 \%$ methanol concentration and $20^{\circ} \mathrm{C}$ ).

\section{Discussions}

Fusaruside is a potential pharmaceutical molecule due to its ability to treat liver injury and colitis through selective immunosuppressive effect. But its poor natural abundance in Fusarium sp. endophytes has become the main bottleneck restricting its further pharmacological research. In this work we sought to produce fusaruside in engineered $P$. pastoris by co-expressing biosynthetic genes, $\Delta 3(\mathrm{E})-\mathrm{SD}, \Delta 10(\mathrm{E})-\mathrm{SD}$ and GCS. A self-processing 2A peptide from FMDV was applied to construct polycistronic systems for gene co-expression in yeast, due to its capacity of simultaneous and efficient expression of multiple genes [16-19]. 2A self-cleavage peptides has been extensively exploited in biomedicine and biotechnology. E.g. A flavone-C-glycoside pathway was 


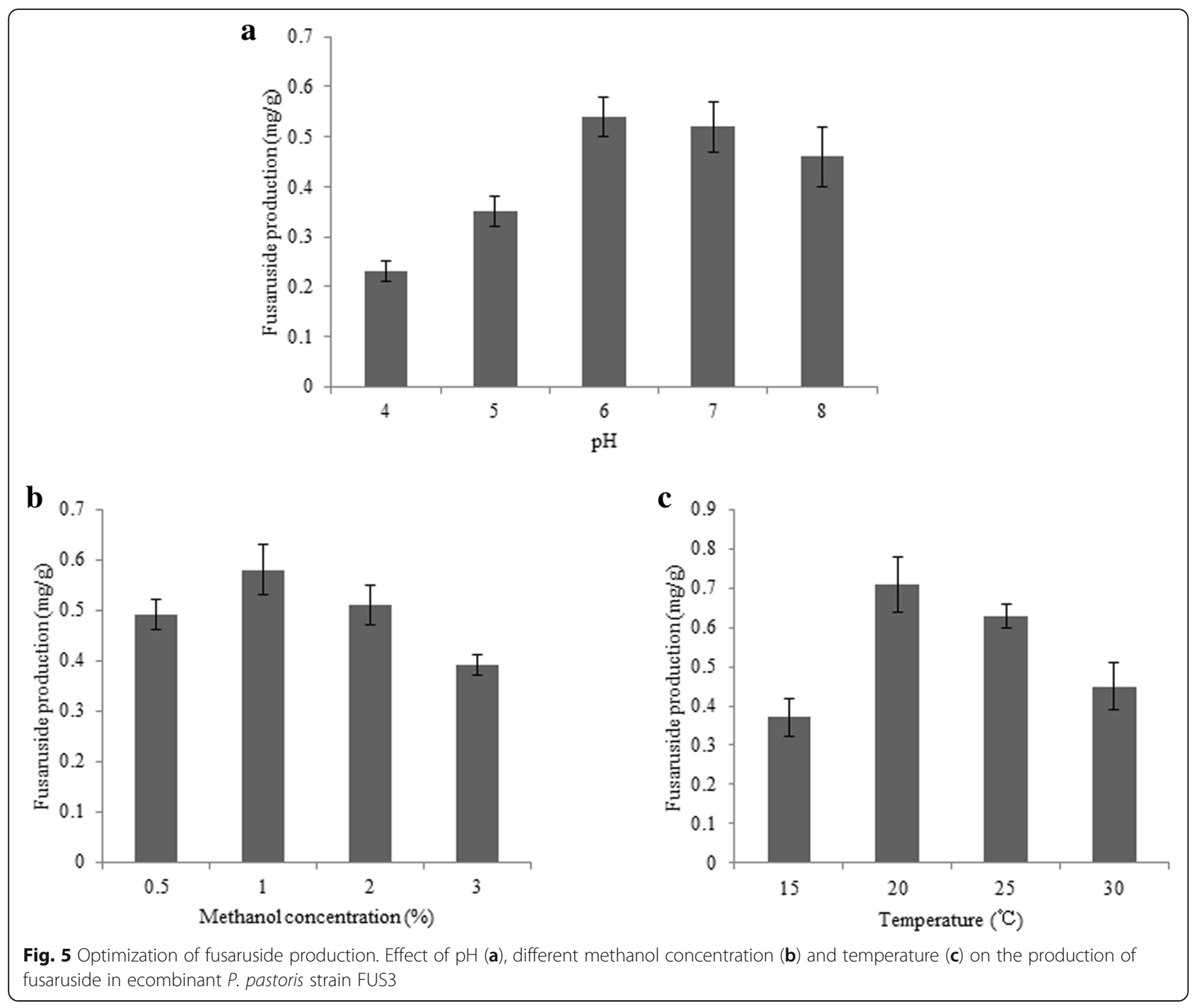

reconstructed in tobacco and yeast using 2A selfcleavage peptide [20]. Similarly, an entire penicillin biosynthesis pathway was rebuilt in Aspergillus nidulans strains using 2A peptide-based system [21]. Geier et al. reported for the first time the functional simultaneous expression of nine genes from a single $2 \mathrm{~A}$ peptide based polycistronic expression construct to produce violacein and carotenoid in P. pastoris [22].

Although the individual expression of $\Delta 3(E)-S D$ and $\triangle 10(\mathrm{E})$-SD in $P$. pastoris has been previously described $[9,10]$. We coexpressed the two enzymes succesfully to realize the production of fusaruside in yeast. Two prominent protein bands representing the two enzymes were produced by clone FUS2 (theoretically in a 1:1 ratio) which is consistent with their co-translational production. LC-MS indicated that the yield of fusaruside produced by FUS2 was $0.39 \pm 0.04 \mathrm{mg} / \mathrm{g}$. To increase the yield further, GCS was also co-expressed with the two desaturases in strain FUS3, because of its importance for sphingolipid biosynthesis in P. pastoris [8]. As we expected, the yield of fusaruside in FUS3 increased to $0.52 \pm 0.06 \mathrm{mg} / \mathrm{g}$.

It has been demonstrated that growth and induction conditions are critical parameters for $P$. pastoris expression systerm [23-25], thus the conditions of FUS3 producing fusaruside were optimized. In this study the optimum $\mathrm{pH}$, methanol concentration and temperature were investigated. $\mathrm{pH}$ may affect the yield of fusaruside through influencing the recombinant enzyme activity. As observed in Fig. 5a, although fusaruside produced at all $\mathrm{pH}$ levels, the maximum yield was at $\mathrm{pH}$ 6.0. Due to the use of inducible $A O X 1$ promoter [14], methanol level can impact the expression of proteins and thus influence the production of fusaruside. A low concetration of methanol cannot induce the promoter efficiently, but excess methanol can lead to an increase of misfolded proteins [26-28]. Here the highest fusaruside production observed at $1 \%$ methanol concentration (Fig. 5b). 
According to many protocols, the optimum temperature for $P$. pastoris cell growth is $30^{\circ} \mathrm{C}$. But in our previous study, the content of fusaruside may increase at lower temperature to resistant cold environment [10]. We asked if lower temperature could enhance the yield of fusaruside in the engineered yeast. When analysing the sphingolipids of FUS3 after $120 \mathrm{~h}$ of induction, the maximum production was observed at $20^{\circ} \mathrm{C}$ (Fig. $5 \mathrm{c}$ ). The growth of Pichia cells declined too much at $15^{\circ} \mathrm{C}$, and therefore fusaruside production was affected. Finally, at optimum condition (pH 6.0, $20^{\circ} \mathrm{C}$ and $1 \%$ methanol concentration) a high level $(0.74 \pm 0.14 \mathrm{mg} / \mathrm{g})$ of fusaruside in yeast FUS3 was achieved after $120 \mathrm{~h}$ induction. Compared to the yield of original Fusarium sp. $(0.12 \mathrm{mg} / \mathrm{g}$ after $10 \mathrm{~d})$ [1], the production in $P$. pastoris was satisfactory.

To further improve the yield of fusaruside, there are still several measures can be done. Except the 2A sequence from FMDV used in this work, there are some other $2 \mathrm{~A}$ sequences, such asthe $\mathrm{P} 2 \mathrm{~A}$ sequence from porcine teschovirus-1 and T2A from Thosea asigna virus [29]. It has been reported that T2A functioned better than other $2 \mathrm{~A}$ sequences and was used to reconstruct carotene biosynthetic pathway in Saccharomyces cerevisiae [30]. Thus different 2A sequences can be considered in further study to enhance fusaruside production. A recent literature indicated that the alteration of the order of genes in the polycistronic $2 \mathrm{~A}$ construct would impact the pathway, and then affect the production of metabolites [31]. This gives us a reminder that the possibility of improving output by changing the order of $\Delta 3(E)$ sd, $\Delta 10(E)$-sd and $g c s$ genes.

\section{Conclusions}

In summary, we reconstituted a heterologous fusaruside biosynthetic pathway by linking three genes, $\Delta 3(E)$-sd, $\Delta 10(E)$-sd and $g c s$, via $2 \mathrm{~A}$ peptide sequences. Thus, the engineered $P$. pastoris yeast can generate fusaruside via glycosphingolipid pathway, and this opens for the use of yeast as a cell factory for production of cerebrosides in future.

\section{Additional file}

Additional file 1: Figure S1. Identification of co-expression plasmid by digestion. a. M: DNA marker; 1: product of double enzyme digestion of pPIC3.5 K - $\Delta 3(E)$-sd $-\Delta 10(E)$-sd. b. M: DNA marker; 1: product of double enzyme digestion of pPIC3.5 $K-\Delta 3(E)$-sd $-\Delta 10(E)$-sd - gcs. Figure S2. Identification of transformants by PCR. a. M: DNA marker; 1-2: PCR products with primer delta3-F/ delta10-R. b. M: DNA marker; 1-2: PCR products with primer delta3-F/gcs-R. Figure S3. ${ }^{1} \mathrm{H}$ NMR of cerebroside B in $\mathrm{CDCl}_{3}(400 \mathrm{MHz})$. Figure $\mathbf{S 4} .{ }^{1} \mathrm{H}$ NMR of fusaruside in $\mathrm{CDCl}_{3}(400 \mathrm{MHz})$. (DOCX $341 \mathrm{~kb})$

\section{Abbreviations}

BMGY: Buffered complex glycerol medium; BMMY: Buffered complex methanol medium; FMDV: Foot-and-month disease virus;

GCS: Glucosylceramide synthase; LC-MS: Liquid chromatography technique coupled with mass spectrometry; NMR: Nuclear magnetic resonance; SDSPAGE: Sodium dodecyl sulfate-polyacrylamide gelelectrophoresis; YNB: Yeast nitrogen base w/o amino acids; YPD: Yeast peptone dextrose medium; $\Delta 10(E)$-SD: delta 10(E)-sphingolipid desaturase; $\Delta 3(E)-S D$ : 2-hydroxy fatty $\mathrm{N}$-acyl-delta3(E)-desaturase

\section{Acknowledgements}

Not applicable.

\section{Authors' contributions}

$Y T, Y L$ and $F Z$ equally contributed in this study. $Y T$ designed and directed the experiments. YL and FZ performed the experiments and analyzed data. $\mathrm{CM}$ edited the manuscript. All authors revised the manuscript. All authors read and approved the final manuscript.

\section{Funding}

This work was supported by the National Natural Science Foundation of China (21602152), Shandong Provincial Natural Science Foundation (ZR2016BB01), Shandong Provincial Key Laboratory of Agricultural Microbiology Open Fund (SDKL2017015), Shandong Provincial Projects of Medical and Health Technology Development Program (2018WS139) and Taian Science and Technology Development Project (2018NS0098). No funding body had any role in the design of the study and collection, analysis, and interpretation of data and in writing the manuscript.

\section{Availability of data and materials}

The datasets supporting the conclusions of this article are available from the corresponding author on reasonable request.

Ethics approval and consent to participate

Not applicable.

Consent for publication

Not applicable.

\section{Competing interests}

The authors declare that they have no competing interests.

\section{Author details}

${ }^{1}$ College of Life Science, Shandong First Medical University \& Shandong Academy of Medical Sciences, Taian 271016, Shandong, China. ${ }^{2}$ Department of Microbiology, College of Life Science, Key Laboratory for Agriculture Microbiology, Shandong Agricultural University, Taian 271018, China.

Received: 22 January 2019 Accepted: 10 June 2019

Published online: 17 June 2019

\section{References}

1. Shu RG, Wang FW, Yang YM, Liu YX, Tan RX. Antibacterial and xanthine oxidase inhibitory cerebrosides from Fusarium sp. IF-121, an endophytic fungus in Quercus variabilis. Lipids. 2004;39(7):667-73.

2. Wang QX, Li SF, Zhao F, Dai HQ, Bao L, Ding R, Gao H, Zhang LX, Wen HA Liu HW. Chemical constituents from endophytic fungus Fusarium oxysporum. Fitoterapia. 2011:82(5):777-81.

3. Wu XX, Sun Y, Guo WJ, Gu YH, Wu XF, Tan RX, Xu Q. Rebuilding the balance of STAT1 and STAT3 signalings by fusaruside, a cerebroside compound, for the treatment of T-cell-mediated fulminant hepatitis in mice. Biochem Pharmacol. 2012;84(9):1164-73.

4. Wu XX, Guo WJ, Wu LM, Gu YH, Gu LY, Xu SH, Wu XF, Shen Y, Ke YH, Tan $R X$, Sun $Y, X u Q$. Selective sequestration of STAT1 in the cytoplasm via phosphorylated SHP-2 ameliorates murine experimental colitis. J Immunol. 2012;189(7):3497-507.

5. Li J, Jie HB, Lei $Y$, Gildener-Leapman N, Trivedi $S$, Green T, KaneLP, Ferris RL PD-1/SHP-2 inhibit TC1/Th1 phenotypic responses and the activation of T cells in the tumor microenvironment Cancer Res. 2015:75(3):1-11.

6. Tan RX, Chen JH. The cerebrosides. Nat Prod Rep. 2003;20(5):509-34. 
7. Black FJ, Kocienski P. Synthesis of phalluside-1 and Sch II using 1,2-metallate rearrangements. J Org Biomol Chem. 2010;8(5):1188-93.

8. Ternes P, Wobbe T, Schwarz M, Albrecht S, Feussner K, Riezman I, Cregg JM, Heinz E, Riezman H, Feussner I, Warnecke D. Two pathways of sphingolipid biosynthesis are separated in the yeast Pichia pastoris. J Biol Chem. 2011;286(13):11401-14.

9. Zäuner S, Zähringer U, LindnerB WD, Sperling P. Indentification and functional characterization of the 2-hydroxy fatty $\mathrm{N}$-acyl-Delta3(E)-desaturase from Fusarium graminearum. J Biol Chem. 2008;283(52):36734-42.

10. Tian Y, Zhao GY, Fang W, Xu Q, Tan RX. $\Delta 10$ (E)-sphingolipid desaturase involved in fusaruside mycosynthesis and stress adaptation in Fusarium graminearum. Sci Rep. 2015;5:10486.

11. Li P, Anumanthan A, Gao XG, llangovan K, Suzara W, Düzgüneş N, Renugopalakrishnan V. Expression of recombinant poteins in Pichia Pastoris. Appl Biochem Biotechnol. 2007;142:105-24.

12. Lin-Cereghino J, Wong WW, Xiong S, Giang W, Luong LT, Vu J, Johnson SD, Lin-Cereghino GP. Condensed protocol for competent cell preparation and transformation of the methylotrophic yeast Pichia pastoris. Biotechniques. 2005;38(1):44-8.

13. Linder S, Schliwa M, Kube-Granderath E. Direct PCR screening of Pichia pastoris clones. Biotechniques. 1996;20:980-2.

14. Dehnavi E, Siadat SOR, Roudsari MF, Khajeh K. Cloning and high-level expression of $\beta$-xylosidase from Selenomonas ruminantium in Pichia pastoris by optimizing of $\mathrm{pH}$, methanol concentration and temperature conditions. Protein Expres Purif. 2016;124:55-61.

15. Gonçalves AM, Pedro AQ, Maia C, Sousa F, Queiroz JA, Passarinha LA. Pichia pastoris: a recombinant microfactory for antibodies and human membrane proteins. J Microbiol Biotechnol. 2013;23(5):587-601.

16. Ahier A, Jarriault $\mathrm{S}$. Simultaneous expression of multiple proteins under a single promoter in Caenorhabditis elegans via a versatile 2A-based toolkit. Genetics. 2014;196(3):605-13.

17. Atkins JF, Wills NM, Loughran G, Wu CY, Parsawar K, Ryan MD, Wang CH, Nelson CC. A case for "StopGo": reprogramming translation to augment codon meaning of GGN by promoting unconventional termination (stop) after addition of glycine and then allowing continued translation (go). RNA. 2007:13(6):803-10

18. Donnelly ML, Hughes LE, Luke G, Mendoza H, Dam ET, Gani D, Ryan MD. The 'cleavage'activities of foot-and-mouth disease virus $2 \mathrm{~A}$ site-directed mutants and naturally occurring '2A-like'sequences. J Gen Virol. 2001;82(Pt5):1027-41.

19. Minskaia E, Nicholson J, Ryan MD. Optimisation of the foot-and-mouth disease virus $2 \mathrm{~A}$ co-expression system for biomedical applications. BMC Biotechnol. 2013;13:67.

20. Brazier-Hicks M, Edwards R. Metabolic engineering of the flavone-Cglycoside pathway using poly protein technology. Metab Eng. 2013:16:11-20

21. Unkles SE, Valiante V, Mattern DJ, Brakhage AA. Synthetic biology tools for bioprospecting of natural products in eukaryotes. Chem Biol. 2014;21(4):502-8.

22. Geier M, Fauland P, Vogl T, Glieder A. Compact multi-enzyme pathways in $P$. pastoris. Chem Commun. 2015;51(9):1643-6.

23. Thiruvengadam G, Init I, Fong MY, Lau YL. Optimization of the expression of surface antigen SAG1/2 of Toxoplasma gondii in the yeast Pichia pastoris. Trop Biomed. 2011;28(3):506-13.

24. Triches Damaso MC, Almeida MS, Kurtenbach E, Martins OB, Pereira J, Andrade CM, Albano RM. Optimized expression of a thermostable xylanase from Thermomycess lanuginosus in Pichia pastoris. Appl Environ Microbiol. 2003;69(10):6064-72.

25. Zhou C, Li D, Wu M, Wang W. Optimized expression of an acid xylanase from Aspergillus usamii in Pichia pastoris and its biochemical characterization. World J Microbiol Biotechnol. 2008;24(8):1393-401.

26. Peña DA, Gasser B, Zanghellini J, Steiger MG, Mattanovich D. Metabolic engineering of Pichia pastoris. Metab Eng. 2018:50:2-15.

27. Santoso A, Herawati N, Rubiana Y. Effect of methanol induction and incubation time on expression of human erythropoietin in methylotrophic yeast Pichia pastoris. Makara Teknol. 2012;16(1):29-34.

28. Hong F, Meinander NQ, Jonsson LJ. Fermentation strategies for improved heterologous expression of laccase in Pichia pastoris. Biotechnol Bioeng. 2002;79(4):438-49.

29. Szymczak AL, Workman CJ, Wang Y, Vignali KM, Dilioglou S, Vanin EF, Vignali DAA. Correction of multi-gene deficiency in vivo using a single 'self-cleaving' 2A peptide-based retroviral vector. Nat Biotechnol. 2004;22(5):589-94.
30. BeekwilderJ v RHM, Koopman F, Sonntag F, Buchhaupt M, Schrader J, Hall $\mathrm{RD}$, Bosch D, Pronk JT, van Maris AJA, Daran J. Polycistronic expression of a $\beta$-carotene biosynthetic pathway in Saccharomyces cerevisiae coupled to B-ionone production. J Biotech. 2014;192:383-92.

31. Jiao X, Sun W, Zhang Y, Liu X, Zhang Q, Wang Q, Zhang S, Zhao ZK. Exchanging the order of carotenogenic genes linked by porcine teschovirus-1 2A peptide enable to optimize carotenoid metabolic pathway in Saccharomyces cerevisiae. RSC Adv. 2018;8:34967-72.

\section{Publisher's Note}

Springer Nature remains neutral with regard to jurisdictional claims in published maps and institutional affiliations.
Ready to submit your research? Choose BMC and benefit from:

- fast, convenient online submission

- thorough peer review by experienced researchers in your field

- rapid publication on acceptance

- support for research data, including large and complex data types

- gold Open Access which fosters wider collaboration and increased citations

- maximum visibility for your research: over $100 \mathrm{M}$ website views per year

At $\mathrm{BMC}$, research is always in progress.

Learn more biomedcentral.com/submissions 